\title{
Synthesis of ZnO-CuO flower-like hetero-nanostructures as volatile organic compounds (VOCs) sensor at room temperature
}

\author{
RaAd S. Sabry, Roonak Abdul Salam A. Alkareem* \\ Department of Physics, College of Science, Al-Mustansiriyah University, Iraq
}

\begin{abstract}
$\mathrm{ZnO}-\mathrm{CuO}$ flower-like hetero-nanostructures were successfully prepared by combining hydrothermal and dip coating methods. Flower-like hetero-nanostructures of $\mathrm{ZnO}-\mathrm{CuO}$ were examined by $\mathrm{X}$-ray diffraction (XRD), field emission scanning electron microscopy (FE-SEM), and UV-Vis. The sensing properties of $\mathrm{ZnO}-\mathrm{CuO}$ flower-like hetero-nanostructures to volatile organic compounds (VOCs) were evaluated in a chamber containing acetone or isopropanol gas at room temperature. The sensitivity of $\mathrm{ZnO}-\mathrm{CuO}$ flower-like hetero-nanostructures to VOCs was enhanced compared to that of pure leafage-like $\mathrm{ZnO}$ nanostructures. Response and recovery times were about $5 \mathrm{~s}$ and $6 \mathrm{~s}$ to $50 \mathrm{ppm}$ acetone, and $10 \mathrm{~s}$ and $8 \mathrm{~s}$ to $50 \mathrm{ppm}$ isopropanol, respectively. The sensing performance of $\mathrm{ZnO}-\mathrm{CuO}$ flower-like hetero-nanostructures was attributed to the addition of $\mathrm{CuO}$ that led to formation of p-n junctions at the interface between the $\mathrm{CuO}$ and $\mathrm{ZnO}$. In addition, the sensing mechanism was briefly discussed.
\end{abstract}

Keywords: hydrothermal process; dip coating; hetero-nanostructures; volatile organic compounds (VOCs)

\section{Introduction}

Volatile organic compounds (VOCs) are organic chemical compounds that have a boiling point less than or equal to $250{ }^{\circ} \mathrm{C}$ at $101.3 \mathrm{kPa}$ pressure (EUROPA, 2004) [1]. VOCs contained in air belong to different groups of compounds such as carbonyl compounds (aldehydes and ketones), aromatic hydrocarbons, alcohols, halogenated hydrocarbons, ethers and others. These compounds are sources of consumer products, such as polishes, paints, cleaning products, glues and sealants. These domestic products have caused about $20 \%$ of poisoning incidents and over $80 \%$ of those incidents were accidental child poisonings [2]. Therefore, it is necessary to monitor the concentrations of VOCs in the environment. Continuous interest is directed toward developing the VOCs sensor with rapid response and recovery times and higher sensitivity to determine and control the VOCs in the environment. To verify these goals, a considerable

*E-mail: roony19882009@yahoo.com attention has been focused on the development of VOCs sensitive to nanomaterials due to their high surface to volume ratio [3].

It is known that a favorite gas sensor should have a combination of longterm stability, high sensitivity and selectivity and low operating temperature. These parameters are mainly dependent on crystal structure, effective surface area, additives and defect density [4].

Semiconductor metal oxides as gas sensing materials have been widely studied for a long time due to their beneficial properties, such as simplicity in fabrication, fast response, ease of fabrication, low cost, small size and low detection limits $(<$ ppm level) [5]. For this reason, some semiconductor metal oxide sensors are used as an effective tool to detect pollutant gases and various VOCs [6]. Among semiconductor metal oxides, zinc oxide $(\mathrm{ZnO})$ is one of the premier materials studied as a gas sensor. This is primarily due to the good thermal and chemical stability under operating conditions and also high mobility of conduction electrons in the material $[7,8]$. 
Table 1. Sensing response behavior of n-type and p-type materials to reducing and oxidizing gases [12].

\begin{tabular}{lccc}
\hline Sensor response behavior & n-type material & p-type material & Example gases \\
\hline \hline Reducing gases & Resistance decreases & Resistance increases & $\begin{array}{c}\mathrm{H}_{2}, \mathrm{H}_{2} \mathrm{~S}, \mathrm{CO}, \mathrm{NH}_{4}, \\
\text { ethanol, acetone, } \mathrm{CH}_{4}\end{array}$ \\
Oxidizing gases & Resistance increases & Resistance decreases & $\mathrm{O}_{2}, \mathrm{O}_{3}, \mathrm{NO}_{\mathrm{x}}, \mathrm{CO}_{2}, \mathrm{SO}_{2}$ \\
Dominant charge carrier & electrons $\left(\mathrm{e}^{-}\right)$ & holes $\left(\mathrm{h}^{+}\right)$ & - \\
\hline
\end{tabular}

It is n-type wide band gap semiconductor $(3.37 \mathrm{eV})$, with a large excited binding energy $(60 \mathrm{meV})$, good photochemical properties, nontoxic and inexpensive. Zinc oxide $(\mathrm{ZnO})$ nanostructures are of particular interest for many applications, such as sensors, catalysts, field emitters and solar cells $[9,10]$. As another important semiconductor metal oxide, copper oxide $(\mathrm{CuO})$ is a kind of intrinsic p-type semiconductor with a narrow band gap. It has great potential as an active catalyst; it is used in solar cells and in gas sensing [11]. Therefore, introducing $\mathrm{CuO}$ may be a more economical and reasonable way to enhance $\mathrm{ZnO}$ gas sensing performance.

During n-type material (majority charge carriers are electrons) interaction with a reducing gas, a decrease in resistance occurs. Conversely, an oxidizing gas serves to deplete the sensing layer of electrons resulting in an increase in resistance. P-type materials (majority charge carrier are holes) exhibit reverse behavior as shown in Table 1 .

To combine the advantages of the $\mathrm{ZnO}$ and the $\mathrm{CuO}$ materials and thus to improve the performance of their combination, a flower-like $\mathrm{ZnO}-\mathrm{CuO}$ hetero-nanostructure has been synthesized and used in this work. $\mathrm{ZnO}-\mathrm{CuO}$ flowerlike hetero-nanostructures were prepared by combining hydrothermal and dip coating methods. Present work investigates the sensitivity of the $\mathrm{ZnO}-\mathrm{CuO}$ flower-like hetero-nanostructures toward VOCs such as acetone and isopropanol at room temperature.

\section{Experimental}

\subsection{Chemicals}

Materials used for preparation included: zinc nitrate hexahydrate $\left(\mathrm{Zn}\left(\mathrm{NO}_{3}\right)_{2} \cdot 6 \mathrm{H}_{2} \mathrm{O}\right.$, Scharlau,
Spain), copper nitrate trihydrate $\left(\mathrm{Cu}\left(\mathrm{NO}_{3}\right)_{2} \cdot 3 \mathrm{H}_{2} \mathrm{O}\right.$, $\mathrm{BDH}$ ), hexamethylenetetramine (HMT, $\mathrm{C}_{6} \mathrm{H}_{12} \mathrm{~N}_{4}$, $\mathrm{BDH})$ and sodium hydroxide (97\% to $100 \%$, $\mathrm{NaOH}$, Scharlau Spain). Distilled water was used throughout the experiments. These materials as well as the measured materials: acetone $(99.9 \%$, $\mathrm{C}_{3} \mathrm{H}_{6} \mathrm{O}$, TEDIA, USA) and isopropanol also called isopropyl alcohol $\left(99.8 \%, \mathrm{C}_{3} \mathrm{H}_{8} \mathrm{O}\right.$, IPA, Ireland) were all used as received.

\subsection{Synthesis process}

\subsubsection{Preparation of $\mathrm{ZnO}$ leafage-like nano- structure}

Zinc oxide $(\mathrm{ZnO})$ leafage-like nanostructure was synthesized using hydrothermal method. $0.1 \mathrm{M}$ of zinc nitrate hexahydrate and hexamethylenetetramine (HMT) were dissolved in $100 \mathrm{~mL}$ distilled water. Then, $0.2 \mathrm{M}$ of $\mathrm{NaOH}$ was added to the mixture under slow stirring for 1 hour at room temperature to adjust $\mathrm{pH}$ of the solution to the value of 10.6, using BP3001 Professional Benchtop pH Meter.

The prepared solution was transferred to an autoclave in an oven and heated to $110{ }^{\circ} \mathrm{C}$ for 5 hours. The obtained white powder was washed several times with distilled water to remove all residues and impurities. Then the prepared powder was added to some amount of distilled water in order to drop it on a substrate (glass or Si wafer) under heating at $50{ }^{\circ} \mathrm{C}$ on a hot plate in air.

\subsubsection{Synthesis of $\mathrm{ZnO}-\mathrm{CuO}$ flower-like hetero-nanostructures}

Zinc oxide $(\mathrm{ZnO})$ leafage-like nanostructures were prepared by hydrothermal method as described in Section 2.2.1. $80 \mathrm{~mL}$ of aqueous solution containing $0.048 \mathrm{wt} \%$ copper nitrate trihydrate and $0.0056 \mathrm{wt} . \%$ hexamethylenetetramine (HMT) were transferred into a $100 \mathrm{~mL}$ glass 
autoclave. Thick films made of $\mathrm{ZnO}$ leafage-like nanostructures were dipped in the aqueous solution of copper nitrate under slow stirring for $30 \mathrm{~s}$. After that, the composite copper nitrate/ZnO leafage-like nanostructures were calcined at $500{ }^{\circ} \mathrm{C}$ for 1 hour to transform the copper nitrate to $\mathrm{CuO}$ through thermal oxidation and obtain $\mathrm{ZnO}-\mathrm{CuO}$ flower-like hetero-nanostructures.

\subsection{Volatile organic compounds (VOCs) sensing}

$\mathrm{ZnO}-\mathrm{CuO}$ flower-like hetero-nanostructures were connected by silver conducting electrode (interdigital electrodes, IDE) using screen printing method. After the electrode deposition, the device was ready for VOCs sensing. The VOCs sensor properties were examined using a home-made testing system. Typically, VOCs sensing measurement was performed in a closed test chamber with an effective volume of $1317.5 \mathrm{~cm}^{3}$ at room temperature. The sensor was placed in the test chamber, and then a given amount of VOCs (acetone or isopropanol) was injected into the chamber by a syringe. The resistance change was monitored by a Keithley 2430 instrument. The sensitivity is defined as:

$$
\left.S(\%)=\mid\left(R_{a}-R_{g}\right) / R_{g}\right) \mid \times 100(\%)
$$

where $\mathrm{Ra}$ and $\mathrm{Rg}$ represent the resistance of the specimen upon exposure to air and gas, respectively [13].

\subsection{Characterization}

The crystalline structure of the specimen was characterized by X-ray diffraction (XRD, Miniflex II Rigaku, Japan) with $\mathrm{CuK} \alpha$ radiation $(\lambda=0.15406 \mathrm{~nm})$. The morphology of the specimen was characterized by field emission scanning electron microscope (FE-SEM, Hitachi-S 4160, Japan) at $15 \mathrm{kV}$ acceleration voltage. Also, UV-Vis measurements of $\mathrm{ZnO}-\mathrm{CuO}$ flower-like hetero-nanostructures were recorded by using a microprocessor UV-Vis spectrophotometer (Double beam LI-2800).

\section{Results and discussion}

Fig. 1a and Fig. 1b show the XRD patterns of $\mathrm{ZnO}$ nanostructures and $\mathrm{ZnO}-\mathrm{CuO}$ flower-like hetero-nanostructures, respectively. After synthesis of $\mathrm{ZnO}-\mathrm{CuO}$ flower-like hetero-nanostructures, three new diffraction peaks were observed at $35.31^{\circ}, 38.91^{\circ}$, and $49.06^{\circ}$, when compared with pure $\mathrm{ZnO}$ nanostructures, which can be attributed to $\left(\begin{array}{lll}0 & 0 & 2\end{array}\right),\left(\begin{array}{lll}2 & 0 & 0\end{array}\right)$ and $\left(\begin{array}{lll}2 & 0 & 2\end{array}\right)$ characteristic peaks of the monoclinic CuO JCPDS Card No. 44-0706, respectively. The peaks at $\left(\begin{array}{lll}1 & 0 & 0\end{array}\right),\left(\begin{array}{lll}0 & 0 & 2\end{array}\right)$, $\left(\begin{array}{lll}1 & 0 & 1\end{array}\right),\left(\begin{array}{lll}1 & 0 & 2\end{array}\right),\left(\begin{array}{lll}1 & 1 & 0\end{array}\right)$, and $\left(\begin{array}{lll}1 & 0 & 3\end{array}\right)$, correspond to hexagonal wurtzite $\mathrm{ZnO}$ (JCPDS Card No. 36-1451). The broadening and small peaks of $\mathrm{CuO}$ nanostructures can be attributed to the small crystallite size and poor crystallinity of $\mathrm{CuO}$ in $\mathrm{ZnO}-\mathrm{CuO}$ flower-like hetero-nanostructures. No peaks for $\mathrm{Cu}_{2} \mathrm{O}$ phase were observed, implying that in the annealing process the copper nitrate completely converted into $\mathrm{CuO}$. Crystallite size was calculated using the Scherrer relation [14]:

$$
D=k \lambda / \beta \cos \theta
$$

where $\mathrm{k}$ is a constant (equal to 0.9 assuming that the particles are spherical), D is the average crystallite size, $\lambda$ is the X-ray wavelength of $0.15406 \mathrm{~nm}$, $\theta$ is the Bragg diffraction angle and $\beta$ is the full width at half maximum. Compared with pure $\mathrm{ZnO}$ nanostructures, the average crystallite size of the $\mathrm{ZnO}-\mathrm{CuO}$ flower-like hetero-nanostructure determined from (1 $\left.\begin{array}{lll}1 & 0\end{array}\right)$ and $\left(\begin{array}{lll}1 & 0 & 1\end{array}\right)$ diffraction peaks decreased from $19.83 \mathrm{~nm}$ to $18.44 \mathrm{~nm}$, which implies that the presence of $\mathrm{CuO}$ nanostructures influences the crystallite size to a certain degree. The average crystallite size of $\mathrm{CuO}$ is $18.80 \mathrm{~nm}$.

Fig. $2 \mathrm{a}$ and Fig. $2 \mathrm{~b}$ show the FE-SEM images of the $\mathrm{ZnO}$ nanostructures $(\mathrm{pH}=10.6)$ at low and high magnifications, respectively. Fig. 2a shows that the specimen has high homogeneity. The $\mathrm{pH}$ of the solution is a critical parameter for particle size, phase formation, and morphology of the structure during the solution growth. As observed in Fig. 2b, the $\mathrm{ZnO}$ has leafage-like nanostructures, whose morphology depends on the $\mathrm{pH}$ value during the solution growth. It is clear that the structure comprises several leafages of about $100 \mathrm{~nm}$ 


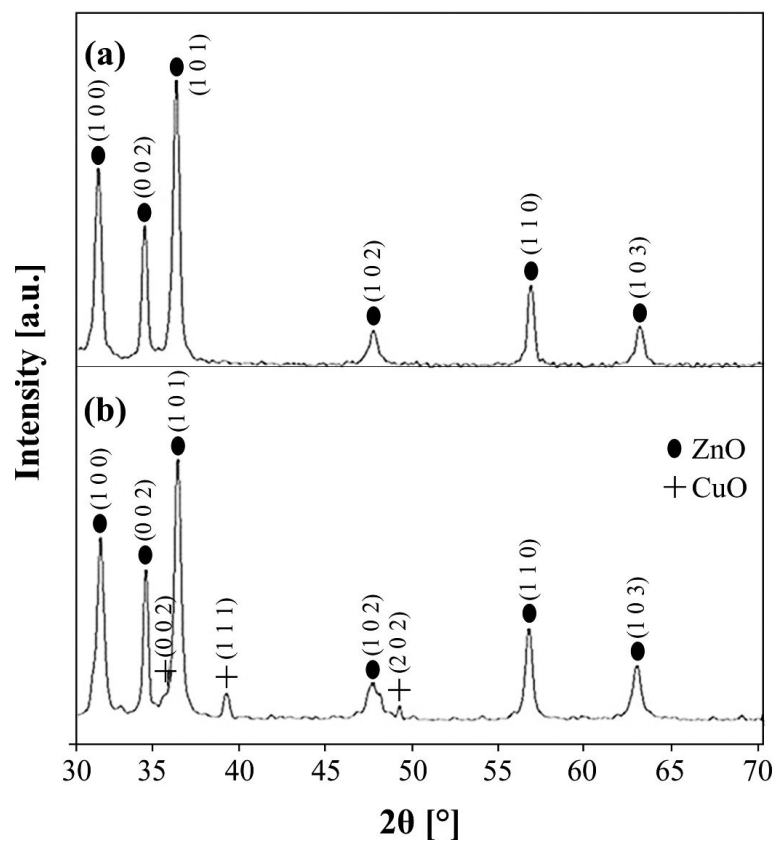

Fig. 1. XRD pattern for (a) $\mathrm{ZnO}$ nanostructures, and (b) $\mathrm{ZnO}-\mathrm{CuO}$ flower-like hetero-nanostructures.

to $700 \mathrm{~nm}$ length and about $50 \mathrm{~nm}$ to $250 \mathrm{~nm}$ thickness. Fig. 2c and Fig. 2d show the morphology of $\mathrm{ZnO}-\mathrm{CuO}$ flower-like hetero-nanostructures at low and high magnifications, respectively. After dip coating and annealing process of the $\mathrm{ZnO}$ nanostructure, the $\mathrm{ZnO}-\mathrm{CuO}$ flower-like heteronanostructures were formed. It can be seen from Fig. 2c that the obtained structure is composed of large quantities of flower-like $\mathrm{ZnO}-\mathrm{CuO}$ heteronanostructures. From the enlarged FE-SEM image in Fig. $2 d$ it is clearly seen that the flower petals exhibit the tapering features with the root size of $100 \mathrm{~nm}$ to $300 \mathrm{~nm}$ and tip size of $50 \mathrm{~nm}$ to $100 \mathrm{~nm}$ approximately.

Fig. 3a shows the typical transmittance spectra of $\mathrm{ZnO}$ nanostructures. The low transmittance percentage below $360 \mathrm{~nm}$ indicates the strong absorbance of $\mathrm{ZnO}$ nanostructures in this region, which has higher energy than the energy gap of $\mathrm{ZnO}$ semiconductor in UV-Vis range. This blue shift is associated with the decrease in crystallite size, which is consistent with XRD results. The band gap of the $\mathrm{ZnO}$ nanostructures is $3.4 \mathrm{eV}$ as shown in Fig. 3b. Fig. 3c shows the optical transmittance of the $\mathrm{ZnO}-\mathrm{CuO}$ flower-like

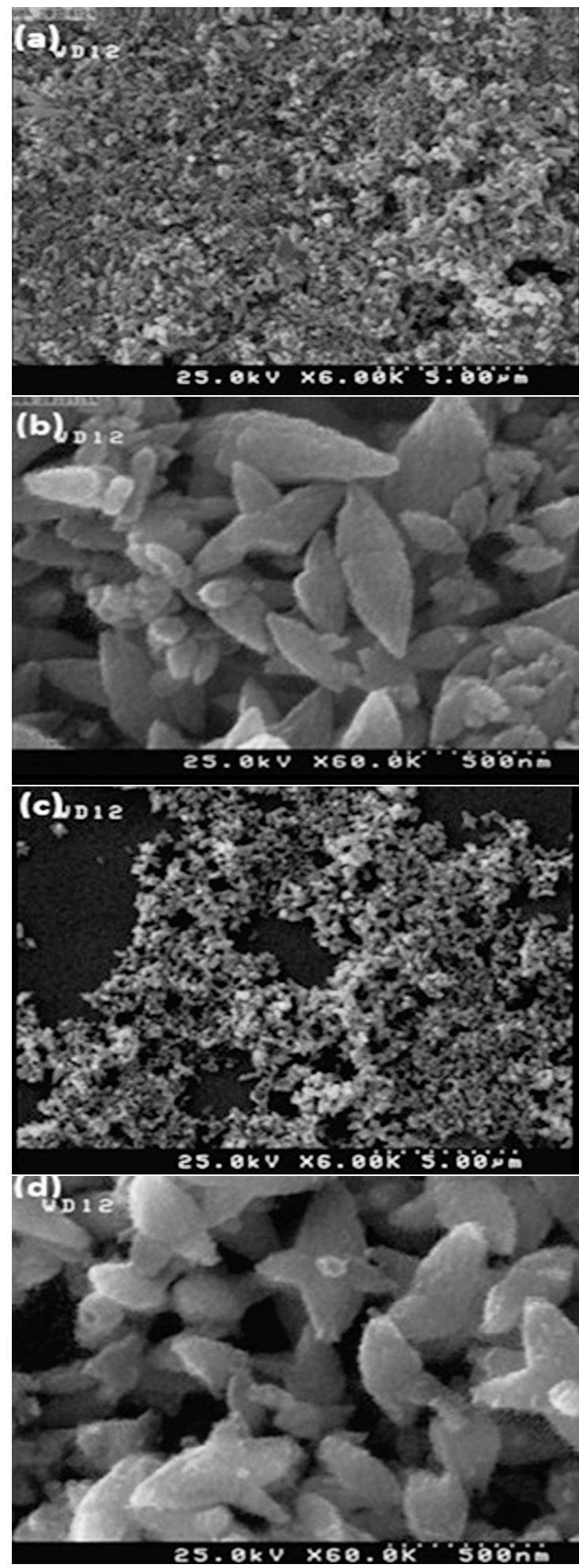

Fig. 2. FE-SEM images of $\mathrm{ZnO}$ leafage-like nanostructure (a) low magnification, (b) high magnification, and $\mathrm{ZnO}-\mathrm{CuO}$ flower-like heteronanostructure (c) low magnification, (d) high magnification. 
hetero-nanostructures. As observed from Fig. 3c there is a low transmittance below $380 \mathrm{~nm}$ indicating the strong absorbance of $\mathrm{ZnO}-\mathrm{CuO}$ flower-like hetero-nanostructures in this region; the red shift is attributed to small band gap of $\mathrm{CuO}(1.2 \mathrm{eV}$ to $1.5 \mathrm{eV})$. The band gap for $\mathrm{ZnO}-\mathrm{CuO}$ flower-like hetero-nanostructures decreased from 3.4 to $3.1 \mathrm{eV}$ compared with pure $\mathrm{ZnO}$ nanostructures as shown in Fig. 3d.

Fig. 4a and Fig. 4b show the transient resistance response of pure $\mathrm{ZnO}$ nanostructures and $\mathrm{ZnO}-\mathrm{CuO}$ flower-like hetero-nanostructures upon exposure to $50 \mathrm{ppm}, 100 \mathrm{ppm}$ and $150 \mathrm{ppm}$ of acetone and isopropanol at room temperature, respectively. It is clear that the resistance of $\mathrm{ZnO}$ nanostructures and $\mathrm{ZnO}-\mathrm{CuO}$ flower-like heteronanostructures initially shows a rapid decline followed by slow decay after injecting VOCs (acetone or isopropanol). However, the resistance rises very fast with time when VOCs was exhausted from the chamber and air was inserted. $\mathrm{ZnO}-\mathrm{CuO}$ flowerlike hetero-nanostructures show n-type gas sensing behavior, that is, the resistance decreases in response to exposing to acetone and isopropanol. The contact of two different types of metal oxide semiconductors results in the formation of $\mathrm{p}$ $\mathrm{n}$ junctions at the interface between the $\mathrm{CuO}$ and $\mathrm{ZnO}$, leading to the decrease in resistance of $\mathrm{ZnO}$ $\mathrm{CuO}$ flower-like hetero-nanostructures compared with the pure $\mathrm{ZnO}$.

The sensitivity of the pure $\mathrm{ZnO}$ leafage-like nanostructure and $\mathrm{ZnO}-\mathrm{CuO}$ flower-like heteronanostructure to different concentrations of acetone and isopropanol (50 ppm, $100 \mathrm{ppm}, 150 \mathrm{ppm}$ ) at room temperature is shown in Fig. $4 \mathrm{c}$ and Fig. 4d, respectively. As observed, the sensitivity to acetone shows higher response compared with isopropanol at room temperature. The sensitivity magnitude is based on the molar volume and the ppm concentration of the VOCs. The molar volume of acetone and isopropanol were $73.42 \mathrm{~cm}^{3} / \mathrm{mol}$ and $76.46 \mathrm{~cm}^{3} / \mathrm{mol}$, respectively. The small molar volume indicates that the molecules can easily diffuse into and effuse out of the specimen [15]. From Fig. 4c and Fig. 4d it can be seen that the $\mathrm{ZnO}-\mathrm{CuO}$ flower-like hetero-nanostructure exhibits higher sensitivity than that of pure $\mathrm{ZnO}$ leafage-like nanostructure in the whole testing range. Table 2 illustrates the response and recovery time of $\mathrm{ZnO}$ nanostructures and $\mathrm{ZnO}-\mathrm{CuO}$ flowerlike hetero-nanostructures. For acetone at the levels of $50 \mathrm{ppm}, 100 \mathrm{ppm}, 150 \mathrm{ppm}$, the sensitivities are about $13.02 \%, 20.21 \%, 43.06 \%$ for $\mathrm{ZnO}$ nanostructures and $14.19 \%, 24.34 \%, 54.96 \%$ for $\mathrm{ZnO}-\mathrm{CuO}$ flower-like hetero-nanostructures, respectively.

According to Maziarz et al. [16], the enhanced sensitivity and response time of $\mathrm{SnO}_{2}$-decorated flower-like $\mathrm{TiO}_{2}$ 3D nanostructures can be attributed to the structure of the sample and using high temperature $\left(308{ }^{\circ} \mathrm{C}\right)$ during the sensing measurements.

Our work shows that the $\mathrm{ZnO}-\mathrm{CuO}$ flowerlike hetero-nanostructures are characterized by enhanced response and recovery times and also increased sensitivity (compared with pure $\mathrm{ZnO}$ nanostructures) at room temperature due to the high aspect surface to volume ratio of the structure which provides many sites to adsorb and desorb gas molecules and also possibility of forming numerous $p-n$ heterojunctions at the interface between $\mathrm{CuO}$ nanoparticles and $\mathrm{ZnO}$ leafage-like nanostructures.

The principle of metal oxide gas sensor mainly depends upon oxygen concentration and its rate of adsorption and desorption. The adsorption can be enhanced by increasing the operating temperature, reducing the grain size, and using dopants. Below the temperature of $200{ }^{\circ} \mathrm{C}$, oxygen molecules in the atmosphere are adsorbed on the sensor surface and form the oxygen ion molecules by attracting an electron from the conduction band of metal oxide semiconductor as shown in the following equation [17]:

$$
\mathrm{O}_{2}(\text { gas })+e^{-}(\text {surface }) \leftrightarrow \mathrm{O}_{2}^{-}(\text {adsorb })
$$

Typically, the sensing mechanism of $\mathrm{ZnO}$ is based on gas adsorption and desorption on the surface of $\mathrm{ZnO}$. When the $\mathrm{ZnO}$ nanostructures sensor is exposed to air, oxygen from the air can be adsorbed on the surface of the $\mathrm{ZnO}$ nanostructures 

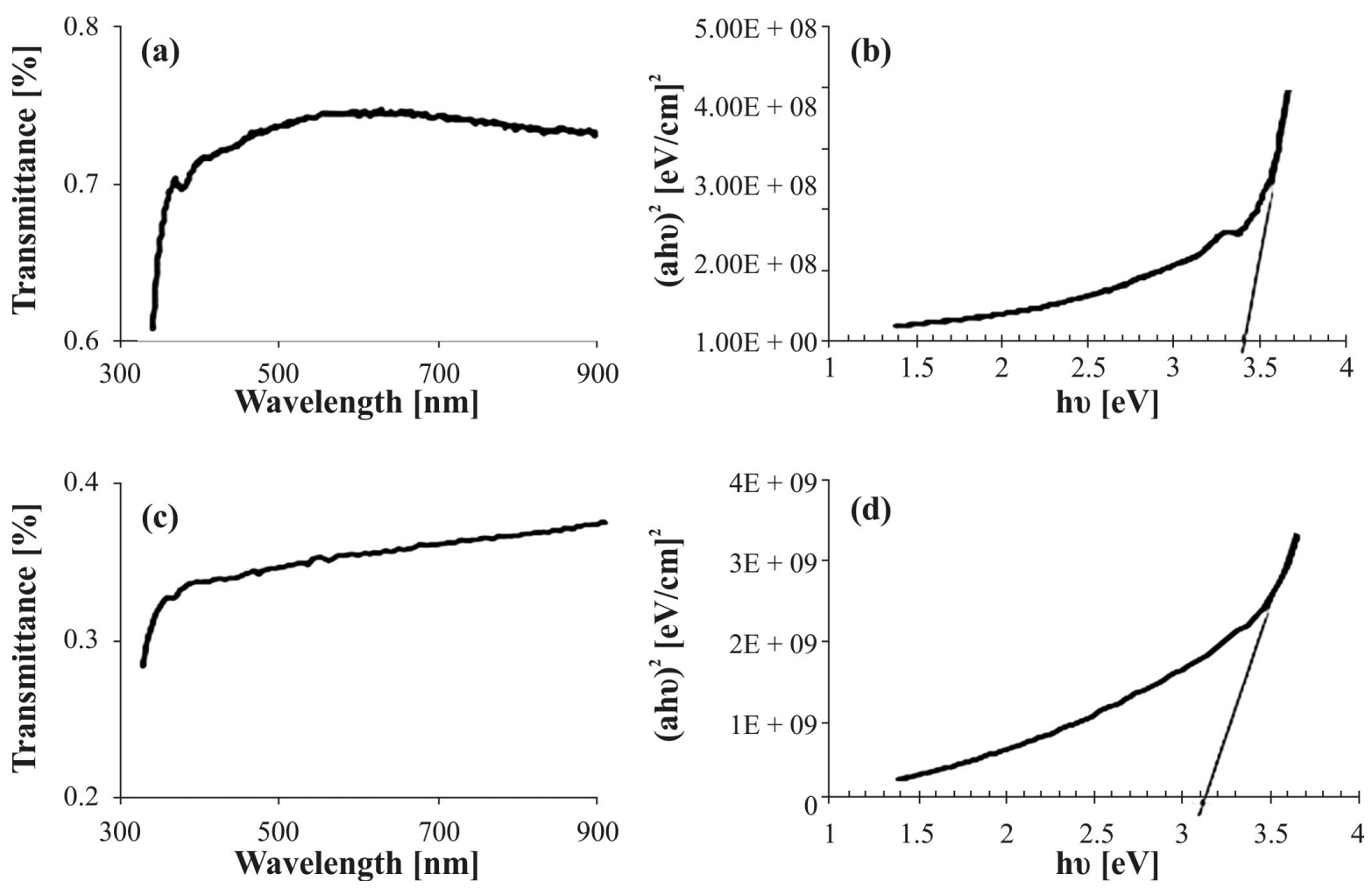

Fig. 3. Transmittance curves for (a) $\mathrm{ZnO}$ nanostructure and (c) $\mathrm{ZnO}-\mathrm{CuO}$ flower-like hetero-nanostructure, $(\alpha \mathrm{h} v)^{2}$ vs. photon energy for (b) $\mathrm{ZnO}$ nanostructure and (d) $\mathrm{ZnO}-\mathrm{CuO}$ flower-like hetero-nanostructure.

and extract electrons from the conduction band of $\mathrm{ZnO}$ nanostructures to form $\mathrm{O}_{2}^{-}$, which can produce a depletion layer on the surface of the nanostructures and result in an increase in sensor resistance [18]. When a $\mathrm{ZnO}$ sensor containing nanostructures is exposed to reductive gases at room temperature, such as acetone or isopropanol vapors, the negative oxygen on surface can react with the reductive gas molecules and release electrons back to the conduction band of $\mathrm{ZnO}$ nanostructures, leading to a decrease in resistance of the sample. The sensing mechanism of $\mathrm{ZnO}-\mathrm{CuO}$ flower-like hetero-nanostructure is somewhat different due to the formation of $\mathrm{p}-\mathrm{n}$ heterojunctions. In air, oxygen molecules capture electrons from $\mathrm{CuO}$ NPs, and chemisorbed oxygen $\mathrm{O}_{2}^{-}$molecules are formed on $\mathrm{ZnO}-\mathrm{CuO}$ hetero-nanostructure surface. Meanwhile, electrons transfer from $\mathrm{ZnO}$ to $\mathrm{CuO}$ resulting in formation electron depletion layer extending into $\mathrm{ZnO}$ [19]. Upon exposure to acetone or isopropanol, the gas molecules react with chemisorbed oxygen $\mathrm{O}_{2}^{-}$and electrons are released to $\mathrm{CuO}$. Then, the electrons return from $\mathrm{CuO}$ to $\mathrm{ZnO}$, leading to the reduction of electron depletion layer thickness, and consequently, the decrease in resistance of $\mathrm{ZnO}-\mathrm{CuO}$ hetero-nanostructures. This can be the operating mechanism of the $\mathrm{ZnO}-\mathrm{CuO}$ flower-like hetero-nanostructures for acetone and isopropanol sensing.

Up to date, many researches have reported on the p-n semiconductor nanostructures used as gas sensors with high operating temperature. In this work, $\mathrm{ZnO}-\mathrm{CuO}$ flower-like hetero-nanostructures exhibited high sensitivity and short response and recovery times to VOCs vapor, which might provide an alternative strategy to improve the VOCs sensing properties of semiconductor nanostructures at room temperature.

\section{Conclusions}

In conclusion, pure $\mathrm{ZnO}$ nanostructures and $\mathrm{ZnO}-\mathrm{CuO}$ flower-like hetero-nanostructures were synthesized by combining hydrothermal and dip 
(a)

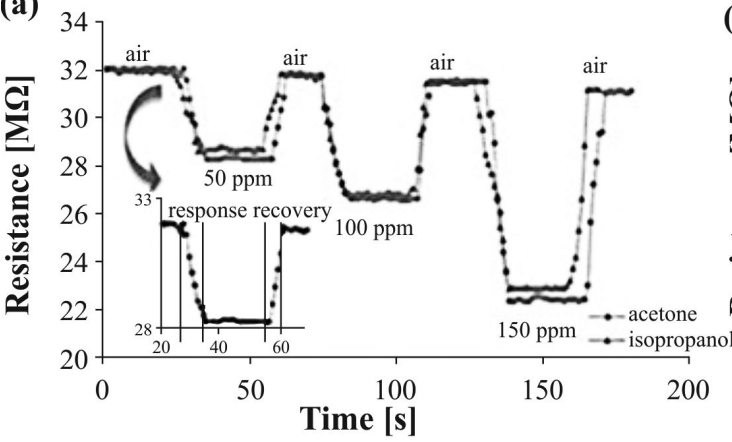

(b)
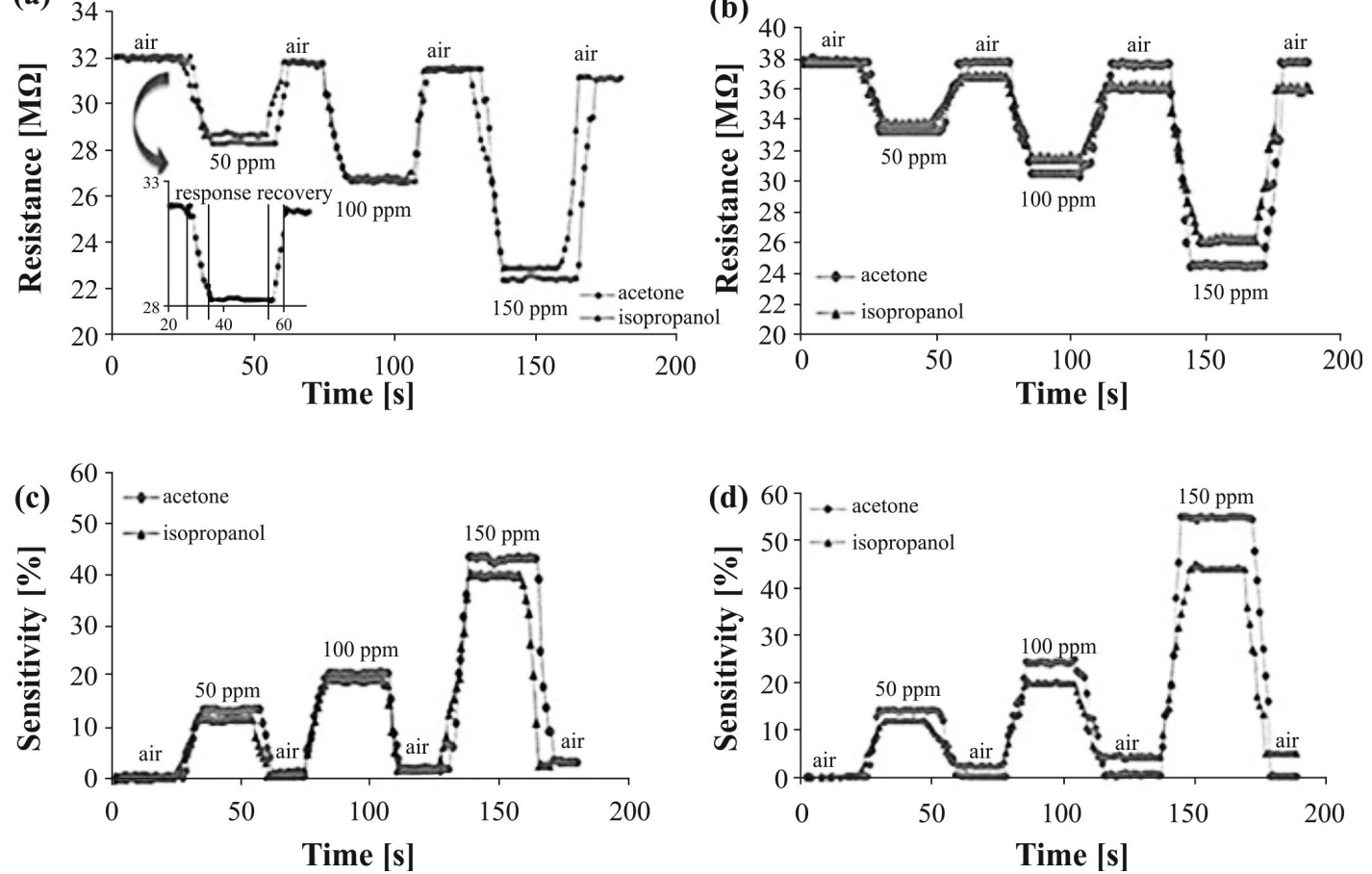

Fig. 4. Transient resistance response of: (a) $\mathrm{ZnO}$ nanostructures (the inset shows response and recovery time for acetone at $50 \mathrm{ppm}$ ), (b) $\mathrm{ZnO}-\mathrm{CuO}$ flower-like hetero-nanostructures; sensitivity of: (c) $\mathrm{ZnO}$ nanostructures, and (d) $\mathrm{ZnO}-\mathrm{CuO}$ flower-like hetero-nanostructures.

Table 2. Response and recovery time of $\mathrm{ZnO}$ nanostructures and $\mathrm{ZnO}-\mathrm{CuO}$ flowers like hetero-nanostructures.

\begin{tabular}{lcccc}
\hline \multicolumn{1}{c}{ Preparation condition } & \multicolumn{2}{c}{ Response time $[\mathrm{s}]$} & & Recovery time [s] \\
\hline \hline \multirow{3}{*}{ Zn nanostructures } & \multicolumn{2}{c}{ Acetone } & $50 \mathrm{ppm}$ & 5 \\
& $50 \mathrm{ppm}$ & 8 & $100 \mathrm{ppm}$ & 5 \\
& $100 \mathrm{ppm}$ & 9 & $150 \mathrm{ppm}$ & 7 \\
\hline \multirow{3}{*}{ Zn-CuO flower-like hetero-nanostructures } & $150 \mathrm{ppm}$ & 10 & $50 \mathrm{ppm}$ & 6 \\
& $100 \mathrm{ppm}$ & 5 & $100 \mathrm{ppm}$ & 12 \\
& $150 \mathrm{ppm}$ & 8 & $150 \mathrm{ppm}$ & 11 \\
\hline \multirow{3}{*}{ Zn nanostructures } & Isopropanol & & & \\
& $50 \mathrm{ppm}$ & 9 & $50 \mathrm{ppm}$ & 6 \\
& $100 \mathrm{ppm}$ & 10 & $100 \mathrm{ppm}$ & 6 \\
& $150 \mathrm{ppm}$ & 11 & $150 \mathrm{ppm}$ & 8 \\
\hline \multirow{2}{*}{ Zn-CuO flower-like hetero-nanostructures } & $50 \mathrm{ppm}$ & 10 & $50 \mathrm{ppm}$ & 8 \\
& $100 \mathrm{ppm}$ & 11 & $100 \mathrm{ppm}$ & 10 \\
& $150 \mathrm{ppm}$ & 13 & $150 \mathrm{ppm}$ & 11 \\
\hline
\end{tabular}

coating methods. Their structural, morphological, to VOCs at room temperature. For the same optical as well as sensing performance were concentration of VOCs, $\mathrm{ZnO}-\mathrm{CuO}$ flower-like investigated. Sensing performance of the hetero-nanostructures show the highest sen$\mathrm{ZnO}$ nanostructures shows good sensitivity sitivity. The enhanced sensitivity and quick 
response/recovery time of these heterostructures at room temperature are explained by the formation of $\mathrm{p}-\mathrm{n}$ heterojunction between $\mathrm{CuO} \mathrm{NPs}$ and $\mathrm{ZnO}$ nanostructures. In addition, the high aspect surface to volume ratio provides more active sites to adsorb and desorb the gas molecules. Also, the decoration of $\mathrm{CuO}$ NPs promotes the chemical reactions and the chemisorption of oxygen species on the surface of $\mathrm{ZnO}-\mathrm{CuO}$ flower-like hetero-nanostructure. The results demonstrate the potential application of $\mathrm{ZnO}$ nanostructures and $\mathrm{ZnO}-\mathrm{CuO}$ flower-like hetero-nanostructures for fabricating high performance VOCs sensors at room temperature.

\section{References}

[1] Dinh T., Choi I., Son Y., Song K., Sunwoo Y., KIM J., J. Environ. Manage., 168 (2016), 157.

[2] Huzar E., Wondnicka A., DzięcioŁ M., Ecol. Chem. Eng. A, 18 (2011), 991.

[3] Gavgani J., Dehsari H., Hasani A., MahYari M., Shalamzari E., Salehi A., Taromi F., RSC Adv., 5 (2015), 57559.

[4] Hosseini Z., Irajizad A., Mortezaali A., Sensor. Actuat. B-Chem., 207 (2015), 865.

[5] Kanan S., El-Kadri O., AbU-YouseF I., KANAN M., Sensors, 9 (2009), 8158.

[6] LeOnardi S., Chemosensors, 5 (2017), 1.
[7] Huang X., Choi Y., Sensor. Actuat. B-Chem., 122 (2007), 659.

[8] Pandya H., Chandra S., Vyas A., Sensor Devices, (2011), 69.

[9] Allaf R., Hope-Weeks L., J. Nanomater, 2014 (2014), 1.

[10] Ramirez A., Ramirez I., Iliana (Eds.), Photocatalytic semiconductors: synthesis, characterization, and environmental applications, Springer, New York, 2015.

[11] Tran T., NguYen V., Int. Sch. Res. Notices, (2014), 1.

[12] Derek R., Sheikh A., Patricia A., Sensor. Actuat. B-Chem, 204 (2014), 250.

[13] Chowa L., Lupana O., Chai G., Khallaf H., Ono L., Roldan C., Tiginyanu I., Ursaki V., Sonte V., Schulte A., Sensor. Actuat. A-Phys, 189 (2013), 399.

[14] Abbas K., Bidin N., Sabry R., Al-Asedy H., AlAzawi M., Islam S., Mater. Chem. Phys., 182 (2016), 298.

[15] Choi J., Park D.W., Shim S.E., Synthetic Met., 162 (2012), 1513.

[16] Maziarz W., Kusior A., Zaiac A.T., Beilstein J. Nanotech., 7 (2016), 1718.

[17] Shankar P., Balaguru Rayayappan J.B., Science Jet, 4(2015), 1.

[18] Al-Hardan N., Abdullah M., Abdul Aziz A., Ahmad H., Low L., Vacuum, 85 (2010), 101.

[19] Chen Y., Shen Z., Jia Q., Zhao J., Zhao Z., Ji H., Roy. Soc. Chem., 6 (2016), 2504.

Received 2017-07-19 Accepted 2018-05-02 